\title{
Shadoo (Sprn) and prion disease incubation time in mice
}

\author{
Sarah E. Lloyd · Julia Grizenkova • \\ Hirva Pota $\cdot$ John Collinge
}

Received: 16 January 2009/Accepted: 13 May 2009/Published online: 10 June 2009

(c) The Author(s) 2009. This article is published with open access at Springerlink.com

\begin{abstract}
Prion diseases are transmissible neurodegenerative disorders of mammalian species and include scrapie, bovine spongiform encephalopathy (BSE), and variant Creutzfeldt-Jakob disease (vCJD). The prion protein (PrP) plays a key role in the disease, with coding polymorphism in both human and mouse influencing disease susceptibility and incubation time, respectively. Other genes are also thought to be important and a plausible candidate is Sprn, which encodes the PrP-like protein Shadoo (Sho). Sho is expressed in the adult central nervous system and exhibits neuroprotective activity reminiscent of $\operatorname{PrP}$ in an in vitro assay. To investigate the role of Sprn in prion disease incubation time we sequenced the open reading frame (ORF) in a diverse panel of mice and saw little variation except in strains derived from wild-trapped mice. Sequencing the untranslated regions revealed polymorphisms that allowed us to carry out an association study of incubation period in the Northport heterogeneous stock of mice inoculated with Chandler/RML prions. We also examined the expression level of Sprn mRNA in the brains of normal and prion-infected mice and saw no correlation with either genotype or incubation time. We therefore conclude that Sprn does not play a major role in prion disease incubation time in these strains of mice.
\end{abstract}

\section{Introduction}

Prion diseases or transmissible spongiform encephalopathies are fatal neurodegenerative disorders and include

S. E. Lloyd $(\bowtie) \cdot$ J. Grizenkova $\cdot$ H. Pota $\cdot$ J. Collinge MRC Prion Unit and Department of Neurodegenerative Diseases, UCL Institute of Neurology, London WC1N 3BG, UK e-mail: s.lloyd@prion.ucl.ac.uk scrapie in sheep, bovine spongiform encephalopathy (BSE) in cattle, and variant Creutzfeldt-Jakob disease (vCJD) in humans. They exhibit a long, clinically silent incubation period and share similar neuropathological signs such as vacuolation, gliosis, neuronal loss, and the accumulation of abnormal forms of the prion protein $\left(\mathrm{PrP}^{\mathrm{Sc}}\right)$.

The prion protein $(\mathrm{PrP})$ plays a central role in prion disease yet its normal function remains elusive. Mice lacking PrP are grossly normal with only subtle abnormalities but are completely resistant to prion infection, thus confirming the central importance of PrP in prion propagation and disease (Bueler et al. 1992, 1993). Mutations in the human prion gene (PRNP) are linked to over 30 inherited forms of human prion disease (Collinge 2001; Mead 2006). Variation in human $\operatorname{PrP}(\mathrm{M} 129 \mathrm{~V})$ is associated with susceptibility to prion disease (Collinge et al. 1991; Mead et al. 2003; Palmer et al. 1991), and polymorphisms in the mouse prion gene, $\operatorname{Prnp}^{a}$ (Leu-108, Thr-189) and Prnp ${ }^{b}$ (Phe-108, Val-189), are associated with short and long incubation times, respectively (Moore et al. 1998; Westaway et al. 1987). Prnp is the main genetic determinant of prion disease incubation time in mice; however, several quantitative trait locus (QTL) mapping studies have demonstrated that other genes are also important (Lloyd et al. 2001, 2002; Manolakou et al. 2001; Moreno et al. 2003; Stephenson et al. 2000). While these studies have been very successful, the genomic regions identified were large and the quantitative trait genes themselves are yet to be identified.

Two paralogs of PrP that share the structural characteristics of PrP have been identified. The Doppel protein (Dpl) is encoded by the Prnd gene and maps adjacent to Prnp on Mmu2. Dpl is normally expressed in testis and plays an important role in spermatogenesis and is unlikely to be relevant in prion disease pathogenesis (Behrens et al. 2002). However, aberrant expression of $\mathrm{Dpl}$ in the 
cerebellum of $\operatorname{Prnp}^{0 / 0}$ mice results in a neurodegenerative phenotype that is rescued by the presence of PrP (Moore et al. 2001; Nishida et al. 1999; Rossi et al. 2001). This is very similar to the results obtained with transgenic mice expressing $\mathrm{N}$-terminal deletion mutants of $\operatorname{PrP}(\Delta \operatorname{PrP})$ (Shmerling et al. 1998). These studies suggested a model that proposes that PrP initiates a cell survival signal through interaction with a ligand $\left(\mathrm{L}_{\mathrm{PrP}}\right)$ that is also able to bind $\mathrm{Dpl}$ and $\Delta \mathrm{PrP}$, albeit with lower affinity. This also led to the suggestion that a PrP-like molecule named $\pi$ could substitute for PrP in the knockout mice, thus explaining their developmentally normal phenotype.

Based on comparative gene analysis, a new PrP-like molecule named Shadoo (Sho, shadow of prion protein) has been identified (Premzl et al. 2003). Sho is encoded by the Sprn gene and maps to Mmu7 (HSA10). Like Prnp, it is predicted to have a glycophosphotidylinositol (GPI) anchor and a conserved hydrophobic region. It has been demonstrated that PrP and Sho have an overlapping, although not identical, pattern of expression in the central nervous system, and like PrP, Sho was able to rescue the neurotoxic phenotype of both $\mathrm{Dpl}$ and $\Delta \mathrm{PrP}$, suggesting that Sho could be a candidate for $\pi$ (Watts et al. 2007). It was also demonstrated that prion-infected mice have a significant reduction in Sho.

Sho has been further implicated in prion disease by the demonstration that a frameshift mutation at codon 46 was found in two vCJD patients but not in controls, and an additional coding polymorphism $(\mathrm{T} 7 \mathrm{M})$ was associated with sporadic CJD (Beck et al. 2008).

Three QTL studies have identified loci on Mmu7 as being linked to prion disease incubation time with suggestive levels of linkage (Lloyd et al. 2001; Moreno et al. 2003; Stephenson et al. 2000). These studies used different mouse and prion strains and the loci were not overlapping. The study of Stephenson et al. (2000) showed a peak of linkage $(\mathrm{LOD}=2.2)$ at marker D7Mit259 which maps within $5 \mathrm{Mb}$ of Sprn.

Taking all these data together, we considered that Sprn was a good candidate gene for prion disease incubation time in mice. In this study we sequenced Sprn to identify polymorphisms and used a heterogeneous stock (HS) of mice to look for an association of Sprn with incubation time. We further examined the level of mRNA expression in the HS parental strains and compared expression in both normal and prion-infected mice.

\section{Materials and methods}

Mice

DNA was obtained from The Jackson Laboratory (Bar Harbor, ME, USA) or as a gift from Jean-Louis Guénet
(Institute Pasteur, Paris). Live MAI/Pas and PWK/Pas mice were obtained from Jean-Louis Guénet; JU/FaCt (gift of Bruce Cattanach) and CAST/Ei were obtained from the Medical Research Council Mammalian Genetics Unit (Harwell, UK). CD-1 mice were obtained from Charles River and all other inbred lines of mice were obtained from Harlan UK Ltd. The Northport Heterogeneous Stock (HS) (gift of R. Hitzemann, Portland, OR, USA) was received as 28 breeding pairs; offspring from these were randomly mated to produce a total of 49 pairs. One thousand fifty-two offspring (generation 37) were used for inoculation. Mice were identified by individual transponder tags (Trovan) and $0.5-\mathrm{cm}$ tail biopsies were obtained for DNA extraction.

\section{Inoculation and phenotyping}

Mice were anaesthetized with isofluorane $/ \mathrm{O}_{2}$ and inoculated intracerebrally into the right parietal lobe with $30 \mu \mathrm{l}$ Chandler/RML prions as previously described (Lloyd et al. 2001). Incubation time was calculated retrospectively after a definite diagnosis of scrapie had been made; it was defined as the number of days from inoculation to the onset of clinical signs (Carlson et al. 1986). This was assessed by daily examination for neurological signs of disease. Animals were culled as soon as clinical scrapie was confirmed or if they showed signs of distress. All procedures were conducted in accordance with UK regulations (Local Ethics approval and Home Office regulation) and international standards on animal welfare.

\section{Statistical analysis}

Incubation time data were collected for 1052 Northport HS mice. The range in incubation time was 103-229 days (mean $\pm \mathrm{SD}=145 \pm 15$ days). The normality of the incubation time distribution was established using the Anderson-Darling normality test $(P=1)$. To look for an association between incubation time and genotype, an ANOVA was used with pairwise comparisons carried out using Fisher's protected least significant difference (PLSD) test (Statview, SAS Institute Inc., Cary, NC, USA).

\section{PCR and sequencing}

DNA was extracted from $0.5-\mathrm{cm}$ tail biopsies using a DNA extraction kit (Promega, Madison, WI, USA) and resuspended in $50 \mu \mathrm{l}$ TE $(10 \mathrm{mM}$ Tris- $\mathrm{HCl}, 1 \mathrm{mM}$ EDTA, $\mathrm{pH}$ 7.5). A 1:10 dilution of this stock was used as template for subsequent PCRs. Oligonucleotides were synthesized by Sigma-Genosys (Sigma-Aldrich, St. Louis, MO, USA). PCR reactions for subsequent sequencing were all carried out in $25 \mu \mathrm{l}$ on 96-well plates using MegaMix Blue (Microzone Ltd, West Sussex, UK) according to the 
manufacturer's instructions and 10 pmol of each primer. PCR conditions were determined empirically but, in general, cycling conditions using a PTC-225 thermal cycler (MJ Research, Waltham, MA, USA) were as follows: $94^{\circ} \mathrm{C}$ for $10 \mathrm{~min} ; 94^{\circ} \mathrm{C}$ for $30 \mathrm{sec}, 60^{\circ} \mathrm{C}$ for $45 \mathrm{sec}, 72^{\circ} \mathrm{C}$ for $60 \mathrm{sec}$ for 40 cycles; $72^{\circ} \mathrm{C}$ for $5 \mathrm{~min}$. PCR products were cleaned using Microclean (Microzone Ltd) according to the manufacturer's instructions and resuspended in $\mathrm{H}_{2} \mathrm{O}$. PCR product (100-200 ng) was added to a $15-\mu l$ sequencing reaction that included $5 \mathrm{pmol}$ of either the forward or the reverse primer, $1 \mu \mathrm{l}$ BigDye Terminator v1.1 Cycle Sequencing Kit (Applied Biosystems, Foster City, CA, USA), and $5 \mu \mathrm{l}$ Better Buffer (Microzone Ltd). Cycling conditions were $95^{\circ} \mathrm{C}$ for $30 \mathrm{sec}, 50^{\circ} \mathrm{C}$ for $15 \mathrm{sec}, 60^{\circ} \mathrm{C}$ for $120 \mathrm{sec}$ for 30 cycles. Reactions were ethanol precipitated, washed in $70 \%$ ethanol, and resuspended in $10 \mu \mathrm{l}$ MegaBACE loading solution (GE Healthcare BioSciences, Piscataway, NJ, USA). Products were detected on a MegaBACE1000 capillary sequencer (GE Healthcare). Samples were injected at $3 \mathrm{kV}$ for $40 \mathrm{sec}$ and run at $9 \mathrm{kV}$ for $100 \mathrm{~min}$.

\section{Allele discrimination}

Primers and probes for Sprn genotyping were designed using criteria defined by Applied Biosystems and PrimerExpress software (Applied Biosystems). MGB probes labeled with either Vic or Fam were purchased from Applied Biosystems and primers for amplification were obtained from Sigma-Genosys. Oligonucleotide sequences were as follows: F-5'-GCCGCACCTTTCCGCT-3'; R-5'-CCTCCCCTACTTACTGGTCACAAG-3'; G-specific probe $5^{\prime}$-Vic-TAGGGGCCGTGACC-MGB-3'; T-specific probe $5^{\prime}$-Fam-TAGGGGCCTTGACC-MGB- $3^{\prime}$. One picomole of each probe and $2.5 \mathrm{pmol}$ of each primer were used in a 5- $\mu 1$ reaction on a 7500 Fast Real-time PCR System (Applied Biosystems) using RoxMegaMix Gold (Microzone Ltd). Cycling conditions were $95^{\circ} \mathrm{C}$ for $5 \mathrm{~min} ; 95^{\circ} \mathrm{C}$ for $15 \mathrm{sec}$ and $60^{\circ} \mathrm{C}$ for $60 \mathrm{sec}$ for 40 cycles.

\section{RNA extraction and quantitative RT-PCR}

RNA was extracted from whole brains from either uninfected or RML terminally sick mice. Six- to eight-week-old adult male mice were used for all normal brains. Tissue was homogenized using a Ribolyser according to the manufacturer's instructions (Hybaid Ltd, Ashford, UK). RNA was prepared using either a RNeasy Maxi kit (Qiagen, Valencia, CA, USA) or a TRIreagent kit (Ambion, Austin, TX, USA) according to the manufacturer's instructions. Samples were treated with DNaseI (Qiagen) and purified further using RNeasy Mini columns (Qiagen) according to the manufacturer's instructions. Four micrograms of total RNA was reverse transcribed with AMV reverse transcriptase and random primers from the Reverse Transcription System (Promega) according to the manufacturer's instructions. Reactions with no reverse transcription were also carried out for each sample to ensure no genomic DNA contamination. Sprn real-time PCR was carried out on a 7500 Fast Real-time PCR System (Applied Biosystems) in a total volume of $15 \mu \mathrm{l}$ using $1 \mu \mathrm{l}$ cDNA (200-300 ng) and RoxMegaMix Gold (Microzone Ltd) according to the manufacturer's instructions. Primers (6 pmol) SPRNF-5'-TGG GCCCGTCTGATTCTG- $3^{\prime}$ and SPRNR-5'-TCAACTATAAGTCCCTCTGGTTCCA- $3^{\prime}$ and probe $(3 \mathrm{pmol}) 5^{\prime}$-Fa m-ACTAAAGCCCCCAAAGACCTTGAGCCTC-Tamra$3^{\prime}$ were designed using PrimerExpress software (Applied Biosystems) and supplied by Sigma-Genosys. Endogenous controls (GAPDH and $\beta$-actin) were VIC-labeled and supplied as a kit by Applied Biosystems. Primers Thy-F-5'-CA GGCACCCTTGGGATACC- $3^{\prime}$ and Thy-R-5'-TGGAACT ATATCCCGACCAACCT- $3^{\prime}$ and probe $5^{\prime}$-Vic-ACGTAC CGCTCCCGCGTCACC-Tamra-3' (Applied Biosystems) for an additional endogenous control, Thy-1, were designed and used as above. Endogenous controls were duplexed with the Sprn reaction according to the manufacturer's instructions or for Thy- 1 using the same primer and probe concentrations as for Sprn. All reactions were carried out in triplicate using the following cycling conditions: $95^{\circ} \mathrm{C}$ for $5 \mathrm{~min} ; 95^{\circ} \mathrm{C}$ for $15 \mathrm{~s}$ and $60^{\circ} \mathrm{C}$ for $60 \mathrm{sec}$ for 40 cycles. Each sample was quantified using all three endogenous controls. The geometric mean of these data was used for statistical analyses and display in Fig. 1.

\section{Results}

Sprn sequencing

To investigate whether coding changes in the mouse Sho protein are likely to influence prion disease incubation time, we sequenced the open reading frame (ORF) of Sprn. The 441-bp (147 amino acids) ORF of Sprn is encoded entirely within exon 2 and is characterised by an N-terminal region containing tetrarepeats rich in arginine and glycine residues, a hydrophobic domain, and an $\mathrm{N}$-glycosylation site (Premzl et al. 2003). We sequenced one mouse DNA sample from each of 24 lines of mice chosen to reflect the three alleles of Prnp (Table 1). The most commonly used inbred lines are all Prnp ${ }^{a}$; however, Prnp ${ }^{b}$ is seen in JU/FaCt and VM/Dk mice, while Prnp ${ }^{c}$ has been recorded only in MAI/Pas mice (Carlson et al. 1988; Lloyd et al. 2004). The Prnp ${ }^{a}$ inbred lines have been demonstrated by us and others to show variation in prion disease incubation time and have been widely used in prion research (Lloyd and Collinge 2005). We also chose lines 

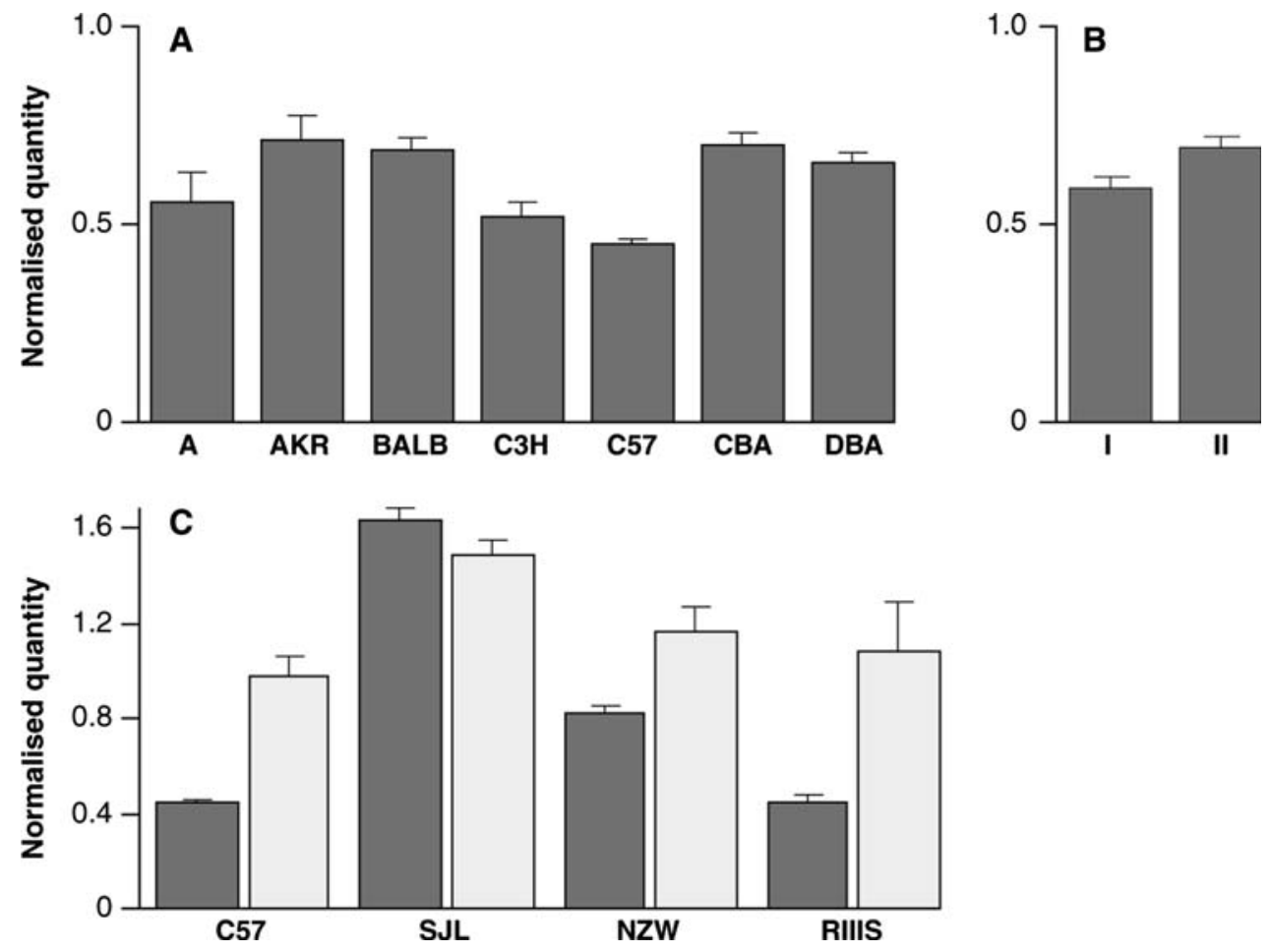

Fig. 1 Sprn mRNA expression. cDNA was prepared from the whole brains of uninfected 6-8-week-old male mice or mice at the terminal stages of disease following intracerebral inoculation with Chandler/ RML mouse-adapted scrapie prions. All samples were duplexed for Sprn (Fam-label) and an endogenous control, GAPDH, $\beta$-actin, or Thy-1 (Vic-label). Samples were run in triplicate with $n=6$ for each mouse strain/group (except CBA where $n=3$ and NZW-RML where $n=5$ ). Mean \pm SEM. Sprn mRNA expression level is expressed in

derived from trapped wild mice, including M. m. musculus (PWK/Pas, MBT/Pas, and MAI/Pas), M. m. domesticus (WLA/Pas and WMP/PAs), $M$. spretus (SEG/Pas), and $M$. $m$. castaneus (CAST/Ei), to capture as much sequence diversity as possible.

Across all 24 strains we detected five polymorphisms in the ORF, only two of which were coding changes (Table 1). Each coding change was seen only in a single line, with G95V and L134F present in CAST/Ei and SEG/Pas, respectively. SEG/Pas was also the only strain for which we detected noncoding polymorphisms at codons 11 (CTG $\rightarrow$ CTA) and 136 (GGC $\rightarrow$ GGT). An additional synonymous polymorphism occurred at codon 108 (GGA $\rightarrow$ GGG), which was seen in four of the wild-trapped mice (MAI/Pas, PWK/Pas, CAST/Ei, and SEG/Pas). No variation was seen across the ORF of the other classical inbred strains. This is of particular interest as this group contains two $\operatorname{Prnp}^{b}$ allele mice. There is considerable variation in incubation time between the inbred Prnp ${ }^{a}$ mice, ranging from $108 \pm 1$ days (NZW) to $143 \pm 1$ days (C57BL/6) (Kingsbury et al. 1983; Lloyd and Collinge 2005; Westaway et al. 1987) even though arbitrary units as normalised by the geometric mean of the quantity of the endogenous controls ( $y$ axis). a Individual parental strains of the HS mice. b Mouse strains are grouped according to the strain distribution pattern seen in Sprn (Group I = A, AKR, BALB, C3H, C57, DBA; Group II = CBA). c Comparison of Sprn mRNA expression in normal and RML infected mice. Dark grey and light grey bars represent uninfected and RML infected mice, respectively

there are no coding polymorphisms in the Sho ORF. This suggests that at least in these strains, variations in the primary sequence of Sho are unlikely to be associated with prion disease incubation time.

The mouse Sprn gene contains a short $5^{\prime}$ UTR (126 bp) spanning exons 1 and 2 and a long $3^{\prime}$ UTR (2586 bp) encoded by exon 2 . The promoter and other regulatory regions have yet to be defined. As it is possible that regulatory regions within the UTRs may influence prion disease incubation time, we extended our sequencing to cover these regions although only in a subset of inbred lines $(\mathrm{A} / \mathrm{J}$, AKR/J, BALB/cJ, C3H/HeJ, C57BL/6 J, CBA/J, DBA/2 J, $\mathrm{LP} / \mathrm{J}$ ) that are the parental strains for the Northport Heterogeneous Stock (HS) (Hitzemann et al. 1994).

Two polymorphisms were seen in the $5^{\prime}$ UTR and one in the $3^{\prime}$ UTR. In addition, four SNPs were seen in the intron 1 sequence flanking the $5^{\prime}$ UTR (Table 2). Only one strain distribution pattern (SDP) was seen with Group I (A, AKR, BALB, C3H, C57BL6, DBA, and LP) having one allele and Group II (CBA) possessing the other variant. These polymorphisms do not occur within any known splicing 
Table 1 Sprn open reading frame polymorphisms
All strains are Prnp ${ }^{a}$ unless otherwise indicated (Carlson et al. 1988; Lloyd et al. 2004)

\begin{tabular}{llllll}
\hline & L11L & G95V & G108G & L134F & G136G \\
& CTG $\rightarrow$ CTA & GGC $\rightarrow$ GTC & GGA $\rightarrow$ GGG & CTT $\rightarrow$ TTT & GGC GGT \\
\hline A/J & G & G & A & C & C \\
AKR/J & G & G & A & C & C \\
BALB/cJ & G & G & A & C & C \\
C3H/HeJ & G & G & A & C & C \\
C57BL6/J & G & G & A & C & C \\
CBA/J & G & G & A & C & C \\
DBA/2J & G & G & A & C & C \\
LP/J & G & G & A & C & C \\
129/Sv & G & G & A & C & C \\
FVB/NHsd & G & G & A & C & C \\
SWR/OlaHsd & G & G & A & C & C \\
NZW/OlaHsd & G & G & A & C & C \\
RIIIS/J & G & G & A & C & C \\
SJL/OlaHsd & G & G & A & C & C \\
JU/FaCt $\left(\right.$ Prnp $\left.^{b}\right)$ & G & G & A & C & C \\
VM/Dk $\left(\right.$ Prnp $\left.^{b}\right)$ & G & G & A & C & C \\
MAI/Pas $\left(\right.$ Prnp $\left.^{c}\right)$ & G & G & G & C & C \\
WLA/Pas & G & G & A & C & C \\
PWK/Pas & G & G & G & C & C \\
WMP/Pas & G & G & A & C & C \\
MBT/Pas & G & G & A & C & C \\
CD-1 & G & G & A & C & C \\
CAST/Ei & G & T & G & C & C \\
SEG/Pas & A & G & G & T & T \\
\hline & & & & & \\
\hline
\end{tabular}

sites, protein, or miRNA binding sites; therefore, it is difficult to predict whether they are likely to be functional.

Sprn genotyping of HS mice

Because the observed SDP is conserved across the gene, we chose one of the $5^{\prime}$ UTR SNPs ( $5^{\prime}$ UTR \#1 in Table 2) to look for an association with prion disease incubation time in the Northport HS. One thousand fifty-two HS mice at generation 37 were inoculated intracerebrally with mouse-adapted scrapie prions (Chandler/RML) and incubation times (in days) were determined as previously described (Carlson et al. 1986; Lloyd et al. 2001). It is recognised that individuals from the ends of a distribution are more likely to share genotypes affecting the phenotype; therefore, selective genotyping from these ends has comparable power to genotyping all individuals (Darvasi and Soller 1992; Lander and Botstein 1989). Therefore, approximately $20 \%$ of animals from each extreme of the incubation time distribution were genotyped. The SNP was genotyped by allelic discrimination using a 7500 RealTime PCR instrument (Applied Biosystems). Genotypes were collected for 348 animals where the genotypes CC
Table 2 HS parental strains Sprn polymorphisms

\begin{tabular}{ccccccccccc}
\hline & $\begin{array}{c}\text { Position } \\
\text { (bp) }\end{array}$ & A & AKR & BALB & C3H & C57 & CBA & DBA & LP \\
\hline 5' UTR & 73 & C & C & C & C & C & A & C & C \\
\#1 & & & & & & & & & \\
5' UTR & 89 & C & C & C & C & C & del & C & C \\
\#2 & & & & & & & & & \\
Intron 1 & 111 & A & A & A & A & A & G & A & A \\
Intron 1 & 143 & C & C & C & C & C & A & C & C \\
Intron 1 & 149 & G & G & G & G & G & C & G & G \\
Intron 1 & 155 & G & G & G & G & G & A & G & G \\
3' UTR & 2024 & G & G & G & G & G & G & G & G
\end{tabular}

SNP positions for the transcript are numbered from the start of the $5^{\prime}$ UTR and the intronic SNPs are shown from the start of intron 1 (genomic sequence from the UCSC genome browser, release July 2007)

del single base deletion, UTR untranslated region

$(n=340)$ and CA $(n=8)$ had mean incubation times of $144.1 \pm 1.2$ and $158.9 \pm 8.4$ days, respectively. Although this suggests that an increase in incubation time may be associated with the presence of the A allele, this is not statistically significant (ANOVA, $P=0.064$ ). 


\section{Sprn mRNA expression}

Transgenic and knockout mouse models have demonstrated that PrP expression levels correlate directly with prion disease incubation time (Büeler et al. 1994; Carlson et al. 1994; Collinge et al. 1995; Prusiner et al. 1990). Although we did not detect any polymorphisms that are predicted to affect Sprn expression, our sequencing was not exhaustive, and particularly since the promoter and other regulatory regions have not been defined, it is possible that we have not identified the key sites. Therefore, we compared the Sprn mRNA expression level in the parental lines of the HS mice. RNA was extracted from whole brains of 8-week-old males from the parental strains of the HS (except LP). Samples were analysed by real-time RT-PCR and normalised using the geometric mean of the quantity obtained from three endogenous controls (GAPDH, $\beta$-actin, and Thy-1). Expression levels for individual strains are shown in Fig. 1a. Although there are differences between the individual strains (ANOVA, $P=0.0007$ ), these differences do not correlate with the known Sprn genotype. This is shown in Fig. 1b where the strains are grouped according to the Sprn SDP (Group I = A, AKR, BALB, C3H, C57, DBA, LP; Group II = CBA). However, if grouped by expression levels, the inbred lines fall broadly into two groups (Group A = A, AKR, BALB, CBA, DBA; Group $\mathrm{B}=\mathrm{C} 3 \mathrm{H}, \quad \mathrm{C} 57) \quad$ that are significantly different $\left(P=6.5 \times 10^{-5}\right)$. If a cis-acting factor were responsible for this, we would expect to see the above grouping reflected in a SDP; however, this has not been observed in our sequencing. Partial low-coverage genome sequence is available for the strains $\mathrm{A} / \mathrm{J}, \mathrm{AKR} / \mathrm{J}, \mathrm{BALB} / \mathrm{cByJ}, \mathrm{C} 3 \mathrm{H} /$ HeJ, C57BL/6 J, and DBA/2J (http://www.informatics.jax. org/); therefore, we searched for SNPs $100 \mathrm{~kb}$ upstream and downstream of Sprn that might correspond to this SDP and did not find any. The strain differences in expression may therefore be explained by a trans-acting factor. We also compared Sprn mRNA expression levels with published incubation times; however, no correlation was observed $\left(R^{2}=0.21\right)$ (Carlson et al. 1994; Kingsbury et al. 1983; Westaway et al. 1987).

It has also been shown that Sho levels are dramatically reduced in prion disease in both $\mathrm{C} 3 \mathrm{H} \times \mathrm{C} 57 \mathrm{~F} 1$ and C57BL6 mice infected with RML prions (Watts et al. 2007). We therefore compared the level of Sprn mRNA expression in the brains of uninfected and terminally sick RML-prion-infected mice from four inbred strains (C57BL/6OlaHsd, SJL/OlaHsd, NZW/OlaHsd, and RIIIS/ J) (Fig. 1c). In contrast to the results obtained by Watts et al. who looked at the Sho protein, the mRNA level was increased in RML infection in three strains (C57BL6, $P=0.0001$; NZW, $P=0.006$; RIIIS, $P=0.013)$ and showed no significant difference in the remaining strain
(SJL, $P=0.1$ ). We also compared the incubation times (Lloyd et al. 2004) with Sprn expression levels in the RML-infected brains and found that no correlation was observed $\left(R^{2}=0.26\right)$.

\section{Discussion}

Our sequencing of the Sho ORF did not identify polymorphisms in the commonly used inbred strains. All variants were found in the strains derived from wild-trapped mice, particularly CAST/Ei and SEG/Pas, which are expected to be more diverse because they belong to the subspecies $M . m$. castaneus and M. spretus, respectively. It is unclear whether these changes would be functionally significant as the amino acid changes do not occur within domains known to be functionally important (Premzl et al. 2003; Watts et al. 2007). Our data suggest that unlike PrP, there is no association of Sho amino acid polymorphisms and prion disease incubation time in mice. This also contrasts with the association of two SPRN frameshift mutations in VCJD and the T7 M polymorphisms with sporadic CJD (Beck et al. 2008).

Although there are no significant coding changes in Sho, it is possible that it exerts its effect on prion disease through variation in expression level either at the level of the mRNA or the protein. The regulation of Sprn is not well characterised; therefore, we were able to look only at the UTRs. We did not sequence our entire mouse panel but focused on the inbred strains that are the parental strains of the Northport HS so that we could use any polymorphism found for an association study. The UTRs were well conserved between the strains, with the only variants seen in the $\mathrm{CBA} / \mathrm{J}$ strain. Because our sequencing was not exhaustive, it is possible that we did not see the functional SNPs and that these represent a different SDP. We genotyped only one marker in the HS mice; however, this represents the only SDP found in the UTRs. No significant association with prion disease incubation time was seen with this SNP although the mean incubation time was 14.8 days longer. This may be due to underrepresentation of the minor allele (A) in the HS. Although we cannot rule out an association of this haplotype with prion disease incubation time in other mouse strains and crosses, we find no genetic evidence of a role for Sprn in our HS mice.

Previous work has shown that Sho levels are reduced by the clinical stage of RML prion infection (Watts et al. 2007). Our data do not replicate this finding. It is possible that this is a reflection of the mouse strains used; however, C57BL/6 was used in both studies, although it should be noted that while we used C57BL/6JOlaHsd (supplied by Harlan, UK), the substrain designation was not specified by Watts et al. An alternative explanation may be that the previous study looked at the protein level while we 
measured the mRNA. Sho-specific antibodies were not available to us; therefore, we considered that measuring the mRNA was a reasonable substitute, particularly as we were interested mainly in measuring cis effects on transcriptional regulation. However, this may not hold true in this case as post-transcriptional mechanisms may inhibit translation or the protein itself may be targeted for degradation.

In conclusion, although Sho is an evolutionary member of the prion protein family, is reported to exhibit PrP-like neuroprotective activity, and is a candidate for the hypothetical $\pi$ protein, our data do not support a major role for Sprn in influencing the natural variation in prion disease incubation time in these strains of mice.

Acknowledgments We are grateful to Jean-Louis Guénet (Institute Pasteur, Paris, France) and Bruce Cattanach (Medical Research Council Mammalian Genetics Unit, Harwell, UK) for the gift of DNA and/or live mice. We also thank Robert Hitzemann (Department of Behavioural Neuroscience, Oregon Health Sciences University, Portland, OR, USA) for the gift of the Northport Heterogeneous Stock of mice, Emma Maytham for preparation of DNA and RNA stocks, David Key and his staff for Biological Services, and Ray Young for preparation of figures. This work was supported by the Medical Research Council, UK.

Open Access This article is distributed under the terms of the Creative Commons Attribution Noncommercial License which permits any noncommercial use, distribution, and reproduction in any medium, provided the original author(s) and source are credited.

\section{References}

Beck JA, Campbell T, Adamson G, Poulter M, Uphill J et al (2008) Association of a null allele of SPRN with variant CreutzfeldtJakob disease. J Med Genet 45:813-817

Behrens A, Genoud N, Naumann H, Rulicke T, Janett F et al (2002) Absence of the prion protein homologue Doppel causes male sterility. EMBO J 21:3652-3658

Büeler H, Fischer M, Lang Y, Bluethmann H, Lipp H-P et al (1992) Normal development and behaviour of mice lacking the neuronal cell-surface PrP protein. Nature 356:577-582

Büeler H, Aguzzi A, Sailer A, Greiner RA, Autenried P et al (1993) Mice devoid of PrP are resistant to scrapie. Cell 73:1339-1347

Büeler H, Raeber A, Sailer A, Fischer M, Aguzzi A et al (1994) High prion and PrPSc levels but delayed onset of disease in scrapieinoculated mice heterozygous for a disrupted PrP gene. Mol Med 1:19-30

Carlson GA, Kingsbury DT, Goodman PA, Coleman S, Marshall ST et al (1986) Linkage of prion protein and scrapie incubation time genes. Cell 46:503-511

Carlson GA, Goodman PA, Lovett M, Taylor BA, Marshall ST et al (1988) Genetics and polymorphism of the mouse prion gene complex: control of scrapie incubation time. Mol Cell Biol 8:5528-5540

Carlson GA, Ebeling C, Yang S-L, Telling G, Torchia M et al (1994) Prion isolate specified allotypic interactions between the cellular and scrapie prion proteins in congenic and transgenic mice. Proc Natl Acad Sci USA 91:5690-5694
Collinge J (2001) Prion diseases of humans and animals: their causes and molecular basis. Annu Rev Neurosci 24:519-550

Collinge J, Palmer MS, Dryden AJ (1991) Genetic predisposition to iatrogenic Creutzfeldt-Jakob disease. Lancet 337:1441-1442

Collinge J, Palmer MS, Sidle KCL, Hill AF, Gowland I et al (1995) Unaltered susceptibility to BSE in transgenic mice expressing human prion protein. Nature 378:779-783

Darvasi A, Soller M (1992) Selective genotyping for determination of linkage between a marker locus and a quantitative trait locus. Theoret Applied Genet 85:353-359

Hitzemann B, Dains K, Kanes S, Hitzemann R (1994) Further studies on the relationship between dopamine cell density and haloperidol-induced catalepsy. J Pharm Exp Therap 271:969-976

Kingsbury DT, Kasper KC, Stites DP, Watson JD, Hogan RN et al (1983) Genetic control of scrapie and Creutzfeldt-Jakob disease in mice. J Immunol 131:491-496

Lander ES, Botstein D (1989) Mapping mendelian factors underlying quantitative traits using RFLP linkage maps. Genetics 121:185199

Lloyd S, Collinge J (2005) Genetic susceptibility to prion diseases in humans and mice. Curr Genomics 6:1-11

Lloyd S, Onwuazor ON, Beck J, Mallinson G, Farrall M et al (2001) Identification of multiple quantitative trait loci linked to prion disease incubation period in mice. Proc Natl Acad Sci USA 98:6279-6283

Lloyd S, Uphill JB, Targonski PV, Fisher E, Collinge J (2002) Identification of genetic loci affecting mouse-adapted bovine spongiform encephalopathy incubation time in mice. Neurogenetics $4: 77-81$

Lloyd S, Thompson SR, Beck J, Linehan J, Wadsworth JD et al (2004) Identification and characterization of a novel mouse prion gene allele. Mamm Genome 15:383-389

Manolakou K, Beaton J, McConnell I, Farquar C, Manson J et al (2001) Genetic and environmental factors modify bovine spongiform encephalopathy incubation period in mice. Proc Natl Acad Sci USA 98:7402-7407

Mead S (2006) Prion disease genetics. Eur J Hum Genet 14:273-281

Mead S, Stumpf MP, Whitfield J, Beck J, Poulter M et al (2003) Balancing selection at the prion protein gene consistent with prehistoric kuru-like epidemics. Science 300:640-643

Moore RC, Hope J, McBride PA, McConnell I, Selfridge J et al (1998) Mice with gene targetted prion protein alterations show that Prnp, Sinc and Prni are congruent. Nat Genet 18:118-125

Moore RC, Mastrangelo P, Bouzamondo E, Heinrich C, Legname G et al (2001) Doppel-induced cerebellar degeneration in transgenic mice. Proc Natl Acad Sci USA 98:15288-15293

Moreno CR, Lantier F, Lantier I, Sarradin P, Elsen JM (2003) Detection of new quantitative trait loci for susceptibility to transmissible spongiform encephalopathies in mice. Genetics 165:2085-2091

Nishida N, Tremblay P, Sugimoto T, Shigematsu K, Shirabe S et al (1999) A mouse prion protein transgene rescues mice deficient for the prion protein gene from Purkinje cell degeneration and demyelination. Lab Invest 79:689-697

Palmer MS, Dryden AJ, Hughes JT, Collinge J (1991) Homozygous prion protein genotype predisposes to sporadic Creutzfeldt-Jakob disease. Nature 352:340-342

Premzl M, Sangiorgio L, Strumbo B, Marshall Graves JA, Simonic T et al (2003) Shadoo, a new protein highly conserved from fish to mammals and with similarity to prion protein. Gene 314:89-102

Prusiner SB, Scott M, Foster D, Pan KM, Groth D et al (1990) Transgenetic studies implicate interactions between homologous PrP isoforms in scrapie prion replication. Cell 63:673-686

Rossi D, Cozzio A, Flechsig E, Klein MA, Rülicke T et al (2001) Onset of ataxia and Purkinje cell loss in PrP null mice 
inversely correlated with Dpl level in brain. EMBO J 20:694702

Shmerling D, Hegyi I, Fischer M, Blättler T, Brandner S et al (1998) Expression of amino-terminally truncated PrP in the mouse leading to ataxia and specific cerebellar lesions. Cell 93:203-214 Stephenson DA, Chiotti K, Ebeling C, Groth D, DeArmond SJ et al (2000) Quantitative trait loci affecting prion incubation time in mice. Genomics 69:47-53
Watts JC, Drisaldi B, Ng V, Yang J, Strome B et al (2007) The CNS glycoprotein Shadoo has $\operatorname{PrP}(\mathrm{C})$-like protective properties and displays reduced levels in prion infections. EMBO J 26:40384050

Westaway D, Goodman PA, Mirenda CA, McKinley MP, Carlson GA et al (1987) Distinct prion proteins in short and long scrapie incubation period mice. Cell 51:651-662 